\title{
Selling the Value of Complex Data-based Solution for Industrial Customers
}

\author{
Tuija Rantala ${ }^{1}$, Tiina Valjakka ${ }^{2}$, Kirsi Kokkonen ${ }^{3}$, Lea Hannola ${ }^{3}$, Mira Timperi ${ }^{3}$ \\ and Leo Torvikoski ${ }^{4}$ \\ ${ }^{1}$ VTT Technical Research Centre of Finland Ltd., PL1306, FI-33101 Tampere, Finland \\ Tuija.Rantala@vtt.fi \\ ${ }^{2}$ VTT Technical Research Centre of Finland Ltd., P.O. Box 1000, FI-02044 VTT, Finland \\ Tiina.Valjakka@vtt.fi \\ ${ }^{3}$ LUT University, PL20, 53851 Lappeenranta \\ \{Kirsi.Kokkonen; Lea.Hannola; Mira.Timperi\}@lut.fi \\ ${ }^{4}$ Eurostep Oy, Metsänneidonkuja 12, FI-02130 Espoo, Finland \\ Leo.Torvikoski@eurostep.com
}

\begin{abstract}
Selling complex data-based solutions is multifaceted as ecosystem actors perceive the value differently during the product lifecycle. The purpose of this paper is to study data-based solution sales in business ecosystems by presenting findings from nine recent interviews with manufacturing industry professionals. The results are demonstrated in two categories: 1) challenges in sharing, selling and buying data, and 2) the value of data for different actors in an ecosystem-like business environment. The managerial implications consist of clarifying the scattered viewpoints for selling data-based solutions and value formulation for different actors in an ecosystem. Theoretical contributions provide important aspects for the gap between business and sales research of data-based solutions, as current literature mainly focuses on the technical aspects.
\end{abstract}

Keywords: data-based service, data-based solution, business-to-business sales, business ecosystem, customer value, manufacturing industry

\section{Introduction}

Developing business with this constantly increasing amount of data raises growing interest in manufacturing companies. Alongside the fast development of digital technologies as well as companies' transition from traditional, product-centred dominant logic to service-centred dominant logic (cf [1]), the data solutions are increasingly composed by several technology components from different providers, and the value of the solution is created via different use cases for several different utilisers along the product lifecycles. Thus, the data-based solutions become more and more complex, both from the standpoint of technology and of utilisation. These complex data-based solutions, such as digital twins and product lifecycle data management services, are also complex to sell and buy, and require a new approach to sales. In value-based selling, it is important that both the buyer and the salesperson are active participants in the two-way communication mapping the buyer's value creation 
potential. Understanding value and selling value are two of the primary components related to selling complex data-based solutions. During the product lifecycle, the value for the buyer can be formulated in different phases, such as design, production or maintenance.

The complexity of data-based solutions demands that companies increasingly adopt ecosystem-based thinking in the development and utilisation of data (e.g., [2]; [3]); the solutions are increasingly provided and utilised in large ecosystem-like environments consisting of several actors, such as OEMs, subcontractors, suppliers, service providers and end customers. In addition, there may be a totally new kind of actor, such as companies, for selling content-related services. All these actors have different needs for the data, and the data also has different impacts on their businesses. Therefore, the sales of complex data-based solutions is multifaceted, while the value may be different for different actors (e.g., [4]; [5]) and thus, there may appear challenges to identify the parties or persons who should, or are willing to pay for the data-based solution or persons who actually initiate the decision-making process.

Current literature related to data-based solutions, for example, digital twins, mainly focuses on the technical aspects and technology or the development of the solution. There is a gap related to the business and especially on sales and customer value aspects concerning data-based solutions. The purpose of this paper is to fill this gap by studying data-based solution sales, especially in a business ecosystem, focusing on customer needs, challenges and value creation. The aim of this paper is to clarify how complex data-based solutions can create value from a B2B sales perspective. We explore the theme by presenting findings from nine recent interviews with data-based solution providers and utilisers from the manufacturing sector. The results are demonstrated related to two categories 1) challenges in sharing, selling and buying data, and 2) the value of data for different actors in ecosystem-like business environment, which is an important viewpoint in selling the data-based solution with proper emphasis on each actor.

The main research question of the study is: How can complex data-based solutions create value from the $B 2 B$ sales perspective? Two sub-questions of the study are as follows:

1. What kind of challenges emerge when selling complex data-based solutions?

2. What kind of industrial needs are there for data-based solutions in a digitally enabled business ecosystem?

\section{Literature Review}

\subsection{Business Ecosystems and the Role of Data}

Digitalisation is increasingly triggering the development of and transition to ecosystembased business $[6,7]$. In the so-called 'digitally-enabled business ecosystems' (e.g., [7]), companies are simultaneously searching for a technological fit of solutions, but are also increasingly aligning their interests, business models and processes in order to co-create value for the end customer, i.e., adopting ecosystem-based thinking (e.g., [3, $1])$. 
One essential element in the growth of these business ecosystems is the data. The continuous innovations in digital technologies have enabled explosive growth in data resources and use cases (e.g., $[8,9])$. For example, in the manufacturing sector, various data in the entire product lifecycles and production processes can be obtained, and developing business with this data raises increasing interest in manufacturing companies $[9,10]$. Companies are increasingly developing and utilising solutions for enabling convergence between a physical system and its digital counterpart, which connect data-driven intelligence and physical knowledge into one model. The level of complexity of these solutions varies a lot, from digital models of a single piece of equipment, to complex and intelligent manufacturing systems utilising digital twins and artificial intelligence [4]. The more complex the data-based solution is, the more likely it is created and utilised among a bunch of different organisations [2]. Complex databased solutions have a lot of business potential at the ecosystem level (e.g. [9]). However, there exist several challenges to tackle, such as how to take over and keep control on the vast amount of data, which can be isolated and fragmented [10]. Another great challenge is that companies' understanding and needs for data-based solutions vary a lot; for example, the definition of a "digital twin" and the needs for its utilisation are highly dependent on the company in question [4, 5]. Thus, development and utilisation of complex data-based solutions require the concretisation of the value of each company involved.

\subsection{Selling Value from Data-based Solutions}

Profiting from data utilisation is still relatively new for many companies. In addition, digital business models in several companies are not structured [11]. There are several theories in the literature related to making profit from data utilisation, e.g., data monetisation [12]. Data monetisation can have several different meanings for researchers and practitioners, such as:

- $\quad$ selling data as a new source for earning in business

- $\quad$ productivity leap by using data

- utilising data in decision-making

- $\quad$ achieving better customer awareness [13]

Fred [14] concluded in her study that data monetisation is divided into two main categories: indirect and direct monetisation. Indirect data monetisation is about creating information-based products and services or data wrapping as a primary or supplementary offering. Direct data monetisation is related to data samples, data packaging or data wrapping as a primary or supplementary offering. However, recent literature is still quite theoretical without practical aspects for earning money from data utilisation, especially in business-to-business (B2B) companies. Our study will provide a practical aspect for selling complex data-based solutions while including an ecosystem perspective.

Selling data-based solutions is about selling value to the customer. These kinds of solutions require understanding of customers' businesses in order to realise the value for the customer. Value-based sales are usually not about the customer's expressed needs, but rather about finding the offering's most valuable benefit for the customer's business [15]. When selling complex data-based solutions, such as digital twins, value 
to a specific customer needs to be recognised and created together with the customer, and the understanding of customers' business and the solution itself is crucial $[16,17]$. With respect to complex data-based solutions, however, the B2B sales perspective is not properly studied in previously published research. Our study will provide new perspectives on a less researched topic, selling complex data-based solutions in digitally enabled business ecosystems.

\section{Methodology}

A qualitative case study was employed as the research methodology in this paper. The case study is suitable for situations and processes containing complex and multiple variables and, therefore, is suitable for this study as well [18]. A case study can be used as an empirical study for examining a phenomenon, e.g., the digital twin concept, especially, with a volatile boundary of phenomenon and real-life contexts [18]. In our study, eight cases were selected where the concept of a complex, data-based solution was examined from a sales point of view. The qualitative data were collected in March 2021 from nine semi-structured theme interviews held with 10 representatives from 8 different large, industrial companies (Table 1).

Table 1. Interviewees

\begin{tabular}{llc}
\hline $\begin{array}{l}\text { Case } \\
\text { company }\end{array}$ & Industry solutions & $\begin{array}{c}\text { Number of } \\
\text { interviewees }\end{array}$ \\
\hline A & for conveying passengers & 1 \\
B & for the marine industry & 1 \\
C & for the refining industry & 1 \\
D & for automation and electric power technology & 1 \\
E & for the marine and energy industry & 1 \\
F & for production machinery & 3 \\
G & for lifting loads & 1 \\
H & for wood processing & 1 \\
\hline
\end{tabular}

The case companies all operate in B2B markets and they can be both providers and utilisers of data-based solutions. They were selected because they are actively developing and taking into use complex data-based solutions, such as digital twins. In addition, they are all established, industrial companies, whose main offering is a big investment for their customers. The case companies are not from one specific business ecosystem but are giving their experiences from several different business environments and ecosystems.

The interviews were recorded and comprehensive notes were taken during each interview by several interviewers. The duration of a typical interview was $1-1.5$ hours, and each involved 1-4 interviewers. The main source of empirical material was semistructured theme interviews, because the study is partly explorative in nature. The area of industrial data-based solutions including ecosystem development and complex data utilisation, is evolving, and the definition of concepts such as complex data-based solutions needed to be negotiated with the interviewees. The interviews went beyond the sale of data-based components of solutions to cover a broad range of themes, such 
as the current utilisation of digital twins, their advantages and challenges, ecosystemic development and customer value and understanding. The approach for analysing the data was content analysis. In several researcher meetings, the primary emerging themes were grouped and analysed.

\section{Findings}

The primary results of the interviews are summarised in Table 2. The first column specifies the interviewed company $(\mathrm{A}-\mathrm{H})$. The second column indicates which kind of challenges and risks emerge when companies are sharing, selling and buying data, and the third column summarises the value of data for different actors in an ecosystem-like business environment.

One of the main challenges was that data can be highly sensitive and cannot be shared in too exact a form. It can cause risks in privacy, cybersecurity, ownerships, or fear of losing information to competitors. However, one interviewee responded that it is more about the safety aspect than a fear of competitors, but the sensitivity side can be seen as a threat as well. Further challenges mentioned were the problems with information flows, especially when there are long subcontractor chains involved. Sometimes it is challenging to correctly interpret the data received from subcontractors. Data is also often fragmented and there is no general view available, thus it becomes hard to process and analyse it. In addition, the vast amount of data causes difficulties to utilise it properly without automation. Equipment tracking and co-scaling of data were also mentioned to be difficult as the product range is wide, lifecycles are long and the equipment may come from different decades. Additionally, storing all the data that keeps building up was seen as a challenge.

The results of the interviews also revealed several industrial needs and the value of data for different actors in an ecosystem-like business environment. The company representatives indicated needs for data-based solutions especially in the middle of the product lifecycle phase, i.e., installed space data for maintenance and modernisation, proactive maintenance and process monitoring data. Further, data about equipment usage was needed, especially concerning how the devices are run, for how long they are run and how large the loads are; this would help design a device that exactly meets the relevant needs. Equipment usage data and "black box"-type information behind fault situations were seen as valuable. However, data needs to be up-to-date and contain a complete product structure of equipment.

The different actors' views in various fields of business highlighted that a clear winwin situation in data sharing has not yet been seen. However, customers have been interested in integration opportunities and exchange of information between systems. One interviewee from the automation and electric power technology industry pointed out that selling data in a standard form could be useful for others as well. Another interviewee saw that easily accessible data would be valuable for subcontractors and logistics operators as well. Further, data exchange between the equipment of different actors would be useful. In general, customers have different data needs; some customers 
produce their products with mass production, others create expensive, customised and high-quality products.

Table 2. Challenges and value of data when selling complex data-based solutions.

Challenges of sharing, selling and buying Needs for data and data value for different
data actors in business ecosystem

A Irregular information flow; Data privacy risks

B Processing and utilising a vast amount of data; finding an appropriate level of data sharing

C Providers' minor role in their customers' business; Equipment tracking: due to a wide product range and long lifecycles; Irregular information flow in long subcontractor chains

D Highly sensitive data; Fragmented data

E Cyber security; Access to data

F Sensitive core business data and technological know-how; Interpreting challenges of subcontractor data

G Data variety from old to new equipment; Getting access to usage data

$\mathrm{H}$ Comprehensive utilisation of physics-based digital twin; fragmented data; varying principles for data sharing
Easily accessible data for subcontractors and logistics operators

Usability of data for predictive maintenance with long life cycle equipment; System integration and data exchange between systems.

Installed base data for maintenance and modernisation; Process reliability data; Data-based tools for distributors related to efficient selling and maintenance

Selling data in a standard form for others; Simulation models for customers

Equipment usage data and a "black box" type of information; Life cycle costs from customers' perspectives

Equipment location data; Win-win situation in sharing has not yet been seen

Equipment usage data

Data exchange between equipment of different providers; customers' varying data needs

Based on the interviews, the business ecosystem from, i.e., the data providers and utilisers are the conventional parties that are involved in design, production, installation, use and maintenance of the equipment. In new product development, the first version of a data-based solution, for example, a digital twin of the physical product, is born, and if a product is very tailored it represents a single physical product which is a long-term investment for the customer company. Suppliers and subcontractors providing systems and subsystems are important data providers in the design and 
manufacturing phases of the case companies' products, and the part of the ecosystem where the needed data is quite readily available.

The vast amount of data is seen as an asset, and the case companies were actively looking for a means of monetising this asset. In all cases, the monetisation was indirect: the case companies have, or are planning to have, data-based business in optimisation of customers' production processes, proactive maintenance or modernisation.

When equipment or machinery is installed and handed over to the customer, there are typically more barriers for data sharing and utilisation, and the parties become more protective of the data they have. When the data is available, in several cases, the main utiliser of data collected from installed base was found in the firm's own R\&D and design department. The data were utilised in designing the next generations of products to better fulfil the customer's needs and requirements.

The data of the installed base is mainly customers (equipment owners, or even their customer) property. The customers typically need a wider view to their production or operations than data related to a single piece of equipment. To gain a systemic view, they need to combine and process data from different manufacturers and service providers. Here the customers can utilise third parties that analyse and process the data. The ecosystem involved is more dynamic at this phase, since, e.g., maintenance partners or suppliers of spare parts can change.

\section{Discussion}

From a data-based solution sales point of view, there is a need for collaboration and partnership where data is shared, and value is co-created among several actors over the product life cycle ( $\mathrm{cf}[1])$. The increased complexity demands companies to see the "big picture" and the value of data in a larger ecosystem. However, the companies often see the data as their own property, as they don't recognise the preferable partners and collaboration opportunities at the ecosystem level. The benefits of business ecosystems are still difficult to perceive, as they demand companies to balance between maximising the ecosystem value, and at the same time, growing their own sales volume (e.g., [19]). The companies seem to be in a phase where the value of the data still needs to be clarified from their own business viewpoint. After that, they can expand the examination of the components of value of other actors and emerging business opportunities of data-based solutions.

Selling data-based solutions is challenging for the interviewed companies, as it requires selling value and understanding the customers' business (e.g., [15], [16]). As one interviewee mentioned, the value is different to different persons in the customer company. Therefore, the data-based solution could be divided into pieces in order to clarify the value from different perspectives and reach out to different buyers in the customer company. In addition, the negotiation position is affecting the data-based solution sales and value sales. When the share of the customer's total solution is small (like 5\%), their negotiation position is very small. The situation will be totally different, if the provider's share of the customer's total solution is high (like 60\%). In the future, business models will change and the possibility to sell, e.g., capacity instead of physical 
products can be easier. Thus, the requirements for data collection and utilisation will increase.

The interviewees shared the opinion that if the customer's operation or usage data were available and combined with the data from previous phases, the companies would be able to offer more value to the customer. Third parties that analyse and process data further are still rare in the ecosystem.

\section{Conclusions}

The managerial implications of this study are for clarifying the scattered concepts around selling complex data-based solutions. This study will help practitioners to benchmark practices in other companies and to give feedback to managers for developing their B2B sales function successfully in practice. Theoretical contributions indicate how data-based solution sales is multifaceted, requires understanding of customer's business and needs, as well as the buying process. Regarding the ecosystemic aspects related to complex, data-based solution sales, the companies are still practising and trying to understand the related ecosystems and their prerequisites, opportunities and challenges.

Our research findings present several practical examples of challenges and value creation related to selling complex data-based solutions. However, our qualitative data is collected from eight large industrial companies and, the interviews were mainly related to their solutions and their customers. In addition, our interviewees occupied more technological positions than on sales positions. For gathering a more thorough understanding of the value of data-based solutions from the perspective of customers, the research could be broadened by interviewing, e.g., actual buyers of the solutions.

Acknowledgments. The authors would like to thank the Digibuzz (Towards Commercial Exploitation of Digital Twins) project and all its parties, as well as Business Finland (the Finnish government organisation for innovation funding and trade, travel and investment promotion) for their support.

\section{References}

1. Yang, M., Evans, S.: Product-service system business model archetypes and sustainability, Journal of Cleaner Production, 220, March, 1156-1166, (2019).

2. Bolton, R.N., McColl-Kennedy, J.R., Lilliemay, C., Gallan, A., Orsingher, C., Witell, L., Zaki, M.: Customer experience challenges: bringing together digital, physical and social realms, Journal of Service Management, vol. 29, no. 5, 776$808,(2018)$.

3. Clarysse, B., Wright, M., Bruneel, J., Mahajan, A. (2014): Creating value in ecosystems: Crossing the chasm between knowledge and business ecosystems, Research Policy, vol. 43, no. 7, 1164-1176, (2014). 
4. Kritzinger, W., Karner, M., Traar, G., Henjes, J., Sihn, W.: Digital twin in manufacturing: A categorical literature review and classification, IFAC-Papers On Line, vol. 51, no. 11, 1016-1022, (2018).

5. Meierhofer, J., West, S., Rapaccini, M., Barbieri, C.: The Digital Twin as a Service Enabler: From the Service Ecosystem to the Simulation Model, In: Nóvoa, H., Dragoicea, M., Kühl, N. (eds.) Exploring Service Science, Proceedings of 10th International Conference, IESS, Porto, Portugal, Feb. 5-7, 2020, Published in Springer: Lecture Notes in Business Information Processing, 377, (2020).

6. Parida, V., Sjödin, D., Reim, W.: Reviewing literature on digitalization, business model innovation, and sustainable industry: Past achievements and future promises, Sustainability, vol. 11, no. 2, 391, 1-18, (2019).

7. Senyo, P.K., Liu, K., Effah, J.: Digital business ecosystem: Literature review and a framework for future research, International Journal of Information Management, vol. 47, 52-64, (2019).

8. Li, X., Cao, J., Zhenggang, L., Luo, X.: Sustainable Business Model Based on Digital Twin Platform Network: The Inspiration from Haier's Case Study in China, Sustainability, vol. 12, no. 3, 936-962, (2020).

9. Olaf, J.M., Hanser, E.: Manufacturing in Times of Digital Business and Industry 4.0 - The Industrial Internet of Things Not Only Changes the World of Manufacturing, in: Hloch, S., Klichová, D., Krolczyk, G., Chattopadhyaya, S. and Ruppenthalová, L. (eds.), Advances in Manufacturing Engineering and Materials. Lecture Notes in Mechanical Engineering, Springer, Cham, 11-17, (2019).

10. Tao, F, Sui, F, Liu, A., Qi, Q., Zhang, M., Song, B., Guo, Z., Lu, S., Nee, A.Y.C., Digital twin-driven product design framework, International Journal of Production Research, vol. 57, no. 12, 3935-3953, (2019).

11. Ulander M., Ahomäki M., Laukkanen J.: The future of European companies in data economy. Sitra 2019. www.sitra.fi / en/ publications/ the- future- ofeuropeancompanies-in- data- economy/, (2019).

12. Hanafizadeh, P., Harati Nik, M.R.: Configuration of Data Monetization: A Review of Literature with Thematic Analysis, Global Journal of Flexible Systems Management, vol. 21, 17-34, (2020).

13. Wixom, B.H.: Cashing in on your Data. Center for Information Systems Research, Sloan School of Management, Cambridge, MA: Massachusetts Institute of Technology. Research Briefing, vol. XIV, no. 8, August, (2014).

14. Fred, J.: Data Monetization - How an Organization Can Generate Revenue With Data?, Master of Science Thesis, Tampere University of Technology, (2017), 66.

15. Terho, H. , Haas, A., Eggert, A., Ulaga, W.: It's almost like taking the sales out of selling' - towards conceptualizing value- based selling in business markets. Industrial Marketing Management, vol. 41, no. 1, (2012), 174-185.

16. Rantala, T., Kokkonen, K., Hannola, L.: Selling digital twins in business-tobusiness markets, in: Ukko, J., Saunila, M., Heikkinen, J., Semken, R.S., Mikkola, A. (eds.) Real-time Simulation for Sustainable Production: Enhancing User Experience and Creating Business Value, Routledge Advances in Production and Operations Management, Routledge, 242, (2021). 
17. Vargo, S.L., Lusch, R.F.: Institutions and axioms: An extension and update of service- dominant logic, Journal of Academy of Marketing Science, 44, 5-23, (2016).

18. Yin R.K.: Case study research: Design and methods (5th ed.). Thousand Oaks, CA: Sage Publications, 282, (2014).

19. Kokkonen, K., Hannola, L., Rantala, Tu., Ukko, J., Saunila, M., Rantala, Te.: Digital twin business ecosystems: Preconditions and benefits for service business. Presented in 21st International CINet Conference, 20-22 Sep, 2020, (2020). 